\author{
Rafael Leite Braz ${ }^{1 *}$, Leif Nutto ${ }^{2}$ Martin Brunsmeier ${ }^{3}$, Gero Becker ${ }^{3}$, Dimas Agostinho da \\ Silva ${ }^{2}$
}

\title{
Resíduos da colheita florestal e do processamento da madeira na Amazônia - uma análise da cadeia produtiva
}

\begin{abstract}
RESUMO
O manejo sustentável da floresta Amazônica é de grande importância para a conservação do bioma, através da utilização racional dos seus recursos, sem levar a total destruição da mesma, minimizando os impactos ecológicos. Uma alternativa de atividade florestal sustentável é o aproveitamento dos resíduos da colheita florestal e do processamento mecânico da madeira. Resíduos oriundos da floresta são desperdiçados, muitas vezes em função de não saberem aproveitá-los ou por falta de opções tecnológicas. A fim de minimizar o desperdício, novas tecnologias devem ser desenvolvidas e empregadas para o aproveitamento e utilização dos resíduos florestais conforme as condições locais, agregando valor à matéria prima, e consequentemente com retorno econômico e social significativo, assegurando a preservação e sustentabilidade dos recursos naturais. $O$ objetivo deste trabalho é de revisar a literatura existente e tentar quantificar os resíduos florestais e da indústria da madeira para incentivar o melhor aproveitamento do mesmo.
\end{abstract}

Palavras-chave: Floresta Amazônica, atividade florestal, aproveitamento dos resíduos

\section{Residues from forest harvesting and wood processing in the Amazon - an analysis of the production chain}

\begin{abstract}
The sustainable management of the Amazon forest is of great importance for the conservation of the biome, minimizing ecological impacts and through the rational use of its resources, without totally destroying the habitat. An alternative sustainable forestry is the use of residues which occur during the harvesting and mechanical processing of wood. Residues from the forest are wasted, often due to not knowing how to leverage them or lack of technological options. In order to minimize waste, new technologies must be developed and employed for the use of forest residues according to local conditions, adding value to the raw material, and consequently raising the economic return and social significance, ensuring the preservation and sustainability of natural resources. The objective of this paper is the review of existing literature and the attempt to quantify residues from forest harvesting and wood processing to encourage the best use of the same.
\end{abstract}

Key words: Amazon Forest, forestry, use of the residues

\footnotetext{
*Autor para correspondência

I*Pós Graduando em Engenharia Florestal, Universidade Federal do Paraná; Curitiba - PR; rafaellbraz@yahoo.com.br

${ }^{2}$ Departamento de Engenharia e Tecnologia Florestal; Universidade Federal do Paraná; Curitiba - PR

${ }^{3}$ Institute Forest Utilization and Work Science, Uni-Freiburg, Germany
} 


\section{INTRODUÇÃO}

$\mathrm{O}$ desenvolvimento de novas tecnologias e alternativas sustentáveis atreladas a gestão ambiental dispõem de um instrumento viável de suma importância que devem ser empregadas de forma consciente dentro do manejo florestal sustentável na região amazônica, de forma a melhorar, viabilizar e aproveitar os resíduos florestais, valorizando os subprodutos. Há a necessidade que as atividades de sustentabilidade nas áreas de manejo florestal ofereçam produtos inovadores a partir de um planejamento e avaliação potencial da utilização racional e eficiente dos recursos florestais. Espera-se que os investimentos contribuam para o uso e manuseio dos resíduos que sobram das atividades de colheita florestal bem como do processo produtivo madeireiro e que possam reverter em lucro e colaborar de forma sustentável conservação do meio, capacitando as florestas a oferecerem serviços e diversos produtos.

A floresta amazônica é uma das maiores florestas tropicais do mundo com características diversas tanto ambiental quanto sociocultural e bastante complexa, de acordo com Higuchi et al. (2006) é a maior reserva contínua de floresta tropical úmida existente, na América do Sul, ocupando uma área de aproximadamente 6 milhões de $\mathrm{km}^{2}$ (Oliveira e Amaral, 2004). Segundo Reis et al. (2010) a Amazônia brasileira representa cerca de um terço das florestas tropicais do mundo, abrigando algumas centenas de espécies de árvores. A Amazônia Legal no Brasil ocupa cerca de 5 milhões de $\mathrm{km}^{2}$, o que corresponde a $60 \%$ do território nacional, ocupado nos estados do Acre (3,64\%), Amapá (2,37\%), Amazonas (37,24\%), Pará (28,12\%), Rondônia (5,13\%), Roraima $(4,13 \%)$ e parte dos estados do Maranhão (3,32\%), Mato Grosso (13,65\%), Tocantins e Goiás (2,40\%) (Higuchi, 1997; Fearnside et al., 1990).

Segundo Oliveira e Amaral (2004) a floresta pode ser dividida em dois grupos: floresta de terra firme e florestas inundáveis. A região da Amazônia brasileira é uma das principais produtoras de madeira tropical no mundo, atrás apenas da Malásia e Indonésia (Organización Internacional de las Maderas Tropicales - OIMT, 2006), com tendência dos volumes anuais colhidos caírem cada vez mais Serviço florestal brasileiro - SFB e o Instituto do Homem e Meio Ambiente da Amazônia - IMAZON (2010).
A floresta amazônica apresenta diversos ambientes, tanto terrestres quanto aquáticos, com diferentes espécies e gêneros da flora e fauna, além dos aspectos dos componentes abióticos, interferindo no equilíbrio e crescimento da floresta, além das relações e interações que podem ocorrer no meio.

A exploração madeireira em florestas naturais ocorre no estuário amazônico desde o século XVII, estando geralmente restrita, até o século XX, às florestas de várzea (Rankin, 1985; Barros e Uhl, 1995; Zarin et al., 2001). Para evitar e combater a exploração irracional e ilegal da floresta, alternativas e estratégias competitivas entre as empresas que praticam o manejo florestal sustentável podem ser usadas para fortalecer e contribuir na proteção e conservação do meio, minimizado o desmatamento e a extração ilegal da madeira que se constituiu ao longo do tempo e precisa ser recuperado atualmente.

Um potencial madeireiro em 60 bilhões de metros cúbicos de madeira em tora foi estimado, com valor econômico potencial de quatro trilhões de reais em madeira serrada, porém não foi feito um comentário pelos autores se este potencial poderia ser utilizado de forma ecológica e sustentável (Barros e Veríssimo, 2002). Entretanto, grande parte desse potencial foi explorada de maneira descontrolada, predatória e impactante, com elevados danos, muitas vezes irreversíveis, o que realça cada vez mais a importância do aproveitamento dos resíduos a partir do manejo florestal sustentável, com benefícios ambientais, sociais e econômicos.

A produção de madeira serrada na região amazônica cresceu nos últimos anos, estimou-se, por exemplo, em 2008 uma produção de 15,1 milhões de $\mathrm{m}^{3}$ de madeira serrada tropical com crescimento de 1,4\% comparado ao ano de 2007 (ABIMCI, 2008). Entretanto, possui um rendimento muito baixo, (41\% no ano de 2009 , por exemplo, segundo o SFB e IMAZON (2010) consequentemente o que contribui para o enorme desperdício de madeira, muitas vezes em função da infraestrutura das serrarias e falta de conhecimento das potencialidades para diversas utilizações que os resíduos podem oferecer. Novas alternativas devem ser criadas para o gerenciamento e aproveitamento dos resíduos florestais oriundos da exploração florestal em diversos setores, potencializando a sua utilização e minimizando o desperdício durante a cadeia de produção, desde a colheita até a obtenção do 
produto final. Muitos problemas ambientais podem ser reduzidos através do consumo dos resíduos do setor florestal.

Vidal et al. (1997) ao investigarem a exploração madeireira na Amazônia, constatou que na região desperdiça, desnecessariamente, um grande volume de madeira, tanto na floresta quanto nas indústrias. Ao avaliar a colheita florestal, pode se observar que isso ocorre muitas vezes quando as toras são derrubadas, mas não são encontradas pelas equipes de arraste, e do mesmo modo, árvores jovens de valor comercial que podem ser colhidas em outros anos são desnecessariamente destruídas. Nas fábricas, os desperdícios ocorrem devido à degradação das toras quando estocadas e quando são serradas incorretamente. Para a regulação da gestão dessas florestas, foi criado o Serviço Florestal Brasileiro responsável por promover o desenvolvimento florestal sustentável no Brasil (Silva et al., 2009), através do acompanhamento e auditoria dos processos de concessão desde a floresta até o produto final.

A utilização dos resíduos florestais como fonte de matéria-prima para a geração de novos produtos, agregando valor e inovação dos subprodutos, altera a ideia de que os resíduos servem apenas como material comburente. A utilização de resíduos florestais, na indústria de processamento, além de reduzir a pressão de exploração de novas áreas e novas árvores, pode proporcionar novas oportunidades de empreendedorismo dentro do manejo florestal e das práticas silviculturais, contribuindo com o crescimento de renda, criando uma nova cadeira de produção com valor agregado e colaborando para a conservação da biodiversidade.

De acordo com Barbosa et al. (2001) o pequeno número de espécies florestais comerciais somados a heterogeneidade da floresta tropical amazônica (200 a 2250 espécies florestais.ha ${ }^{-1}$ ) fazem com que o rendimento de madeira por hectare seja baixo. Reis (1989) citado por Pontes (2011), relatou que dos 230 a $280 \mathrm{~m}^{3} \cdot \mathrm{ha}^{-1}$ do volume de madeira da região Amazônica, apenas $10 \%$ chegam às serrarias, $49 \%$ são usados como lenha e o restante é descartado como resíduo florestal. Ao conhecer a quantidade e qualidade dos resíduos florestais e madeireiros, criam-se soluções e possibilidades de uso com potencial, Observa-se o elevado desperdício, uma vez que poderiam ser aproveitados como alternativa de renda, promovendo a fabricação de novos produtos como briquetes, pequenos objetos de madeira, entre outros.

O setor florestal madeireiro é uma das atividades mais dinâmicas e paradoxais de uso da terra sob um regime de manejo sustentável que é capaz de conciliar conservação e também o desenvolvimento Veríssimo et al. (1995), uma vez que a necessidade de desenvolver sistemas de produção sustentável, social e politicamente ambiental é uma preocupação marcante nos últimos anos para as indústrias do setor.

A utilização dos recursos provenientes da floresta e sua importância para o desenvolvimento sócioeconômico têm ganhado lugar de destaque, no qual vêm acarretado fortes pressões para que os países busquem estratégias que levem alternativas de uso racional dos recursos florestais, através de tecnologia adequada às condições regionais, permite a redução de desperdícios, o aumento da rentabilidade, à geração de emprego e renda, permitindo a redução da intensidade de exploração, com melhorias da qualidade ambiental e social (Pontes e Afonso, 2010).

Conforme o relato no presente trabalho, a quantidade de resíduos florestais desperdiçados envolve toda a cadeia produtiva, desde a colheita até a obtenção do produto final, principalmente durante a extração das árvores uma vez que a maioria possui um elevado porte. Muitos estudos relacionados ao aproveitamento de resíduos têm como foco a utilização da madeira descartada durante $\mathrm{o}$ processo de desdobro, mas ao acompanhar o processo de corte durante a colheita florestal, observa-se que o volume de madeira da copa das árvores que ficam em campo é significativo, consequentemente, isto pode proporcionar um novo processo produtivo (Pontes et al., 2012). Por outro lado, o que impede muitas vezes o desenvolvimento de uma nova cadeia de produção e o grande volume considerável da biomassa (galhos e copas das árvores) deixados na floresta é a falta de valor agregado de forma eficiente a este material.

Garcia (2011) ao estudar algumas espécies florestais, ressalta que o aproveitamento de resíduos das galhadas de árvores exploradas para fins de madeira serrada é uma alternativa que agrega valor ao resíduo que antes era vendido na sua forma bruta, e pode ser beneficiado e vendido a um valor maior.

$\mathrm{O}$ aumento e melhorias no aproveitamento de resíduos com a otimização do uso da madeira contribui na redução dos efeitos da potencial 
escassez. Nesse sentido, torna-se relevante a disseminação de ideias para as empresas empregarem novas técnicas de classificação, estimar a quantidade de resíduos gerados, planejarem formas de armazenamento, transporte e transformação em subprodutos de maior valor agregado, Instituto Brasileiro de Qualidade e Produtividade do Paraná - IBQP (2002).

Neste contexto o estudo do aproveitamento dos resíduos é de grande importância e visa encontrar soluções e novas tecnologias que possam ser implementadas, potencializando a utilização dos resíduos de forma sustentável e viável com um retorno econômico considerável, e minimizando os impactos no meio, o que contribui para a preservação dos recursos florestais.

O presente trabalho trata-se de uma revisão bibliográfica acerca do aproveitamento e quantificação dos resíduos florestais na região Amazônica provenientes da colheita florestal e do processamento mecânico da madeira nas serrarias, assegurando a sustentabilidade florestal. O estudo também foi construído através da análise de dados já citados na literatura e da base de dados da Empresa Orsa Florestal S/A oriundos do inventário florestal.

\section{MANEJO FLORESTAL SUSTENTÁVEL DA FLORESTA AMAZÔNICA}

A legislação brasileira define o manejo florestal sustentável como "a administração da floresta para a obtenção de benefícios econômicos, sociais e ambientais, respeitando-se os mecanismos de sustentação do ecossistema objeto do manejo e considerando-se, cumulativa ou alternativamente, a utilização de múltiplas espécies", possui exigências para alcançá-lo (Brasil, 2009).

A gestão das florestas naturais do Brasil tem três grandes desafios: 1-manter e ampliar a cobertura florestal, 2-ampliar as áreas de proteção integral em áreas de alto valor para conservação, e 3promover o desenvolvimento socioeconômico, a partir do uso sustentável das florestas (REMADE, 2007). A utilização racional da floresta amazônica significa o equilíbrio de vários fatores e funções que garantem o funcionamento de seu conjunto de ecossistemas, fornecendo benefícios importantes na forma de serviços ambientais que são frequentemente necessários para a sustentabilidade econômica (Higuchi, 1994).

Vários autores ressaltam que a degradação de florestas amazônicas tem sido acelerada devido a incertezas sobre a posse da terra e dos recursos florestais, falhas nos sistemas de comando e controle, práticas inadequadas do manejo florestal e incentivos perversos para a conversão de florestas a agropecuária (Sabogal et al., 2006; Uhl et al., 1997).

Para Scolforo et al. (1996) a suscetibilidade das espécies florestais a exploração, a economicidade do manejo sustentado, maior eficiência no processo de beneficiamento e aproveitamento da madeira, a racionalização das técnicas de exploração e transporte, dentre outros, são pontos relevantes para que as florestas naturais possam ser utilizadas em bases sustentadas.

De acordo com Gama et al. (2005) a garantia de uma produção contínua de madeira, associada à conservação da biodiversidade de florestas nativas como a Amazônia, pode ser alcançada mediante o manejo florestal sustentável. Os mesmos autores ressaltam que a finalidade do manejo florestal é conseguir que as florestas forneçam continuamente benefícios econômicos, ecológicos e sociais, mediante um planejamento mínimo para $\mathrm{o}$ aproveitamento dos recursos madeireiros e nãomadeireiros disponíveis.

Os impactos da exploração madeireira em florestas nativas, levando-se em consideração os danos causados aos indivíduos arbóreos, regeneração natural e solo, devem ser observados criteriosamente no manejo destas florestas, pois estes impactos têm influência direta na elaboração do plano de manejo, além da busca pelas questões básicas, ligadas a auto-ecologia das espécies envolvidas (Martins et al., 2003).

Diversos autores (Sist e Ferreira, 2007; Gonçalves e Santos, 2008) alegam que os estudos que comparam os tipos de exploração verificam a real eficácia e propõe novas metodologias que ajudem a garantir a sustentabilidade da floresta é importante devido ainda possuir pouco conhecimento sobre o verdadeiro impacto proveniente da exploração madeireira em florestas tropicais (Nutto et al., 2009).

Para Higuchi et al. (2008), entre os vários recursos naturais da Amazônia, a madeira é, sem dúvida, o que tem a maior liquidez, e deve ser considerada como produto de primeira necessidade. Entretanto, Schneider e Finger (2000) ressaltam que a produção sustentada desse recurso no longo prazo requer, indiscutivelmente, a manutenção de condições ecológicas ótimas da floresta, bem como o retorno econômico, sem o qual não haverá sustentabilidade. 
O uso dos resíduos oriundos da colheita florestal e do processamento da madeira para a obtenção de um produto final e demais finalidades que agregam valor a matéria prima deve fazer parte do manejo florestal sustentável na região amazônica.

\section{ESTIMAÇÃO DO VOLUME DE RESÍDUOS FLORESTAIS E} INDUSTRIAIS

Brand et al. (2002) citam que a forma mais adequada do conhecimento necessário para a solução destes problemas passa pela caracterização do rendimento produtivo das indústrias, dos fatores geradores de resíduos, do volume e tipos de resíduos existentes, da sazonalidade de geração dos mesmos, além dos possíveis usos que podem ser dados a este material. Segundo Baggio e Carpanezzi (1995) o conhecimento da quantidade e da qualidade dos resíduos florestais permite avaliar o seu potencial de aproveitamento.
Para exemplificar o quanto é elevado o desperdício de madeira, um estudo realizado pelo SFB e IMAZON (2010), registraram que no ano de 2009 foi processado 14,2 milhões de metros cúbicos de madeira em tora, o que resultou na produção de 5,8 milhões de metros cúbicos de madeira processada. A maioria $(72 \%)$ dessa produção era madeira serrada com baixo valor agregado, os outros $15 \%$ foram transformados em madeira beneficiada com algum grau de agregação de valor, o restante (13\%), em madeira laminada e compensada. Isso representou um rendimento médio de processamento de $41 \%$. Os outros 8,4 milhões de madeira em tora foram categorizados como os resíduos do processamento (Figura 1). Desse total, cerca de 1,6 milhão de metros cúbicos desses resíduos foram aproveitados na produção de carvão, outros 2,7 milhões, na geração de energia, e 2,0 milhões, em usos diversos. Os 2,1 milhões restantes foram considerados resíduos sem nenhum aproveitamento, os quais foram queimados ou abandonados como entulho.

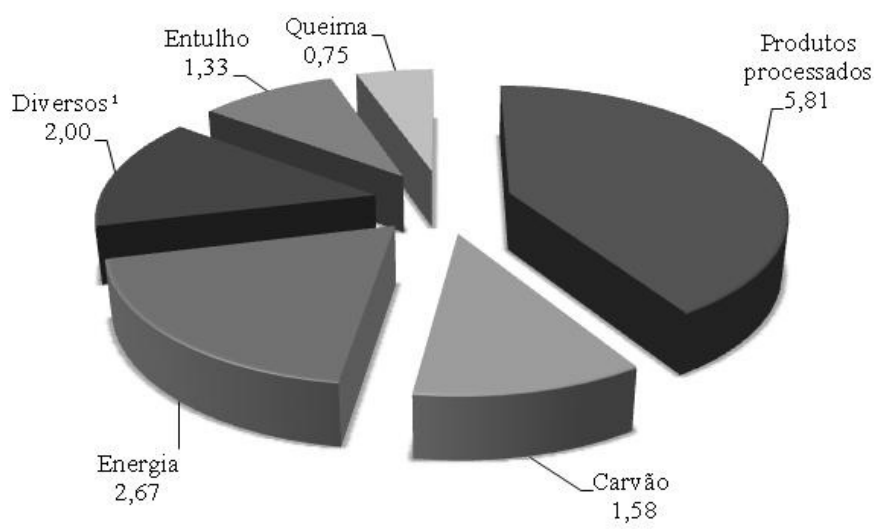

Figura 1. Usos da madeira nativa da região amazônica (em milhões de $\mathrm{m}^{3}$ de tora). Adaptado de SFB e IMAZON (2010).

*11 Inclui o aproveitamento dos resíduos como adubo, em aterros, lenha, entre outros.

Para demonstrar a situação do aproveitamento e desperdício de madeira na região amazônica foi estimado o volume com base em dados da empresa ORSA Florestal S/A em um estudo de caso e dos demais dados encontrados na literatura. A área de estudo foi de 590 hectares onde foi levantado o número de indivíduos, frequência das espécies e quantificação do resíduo oriundo da colheita até o processamento das toras de madeira nas serrarias. Observa-se na figura 2 que a espécie de maior frequência foi à maçaranduba (Manilkara bidentada (A. DC.) A. Chev. ), seguida pela cupiúba (Goupia glabra Aublet), mandioqueira escamosa (Qualea paraensis Ducke), angelim vermelho (Dinizia excelsa Ducke) e demais espécies. 


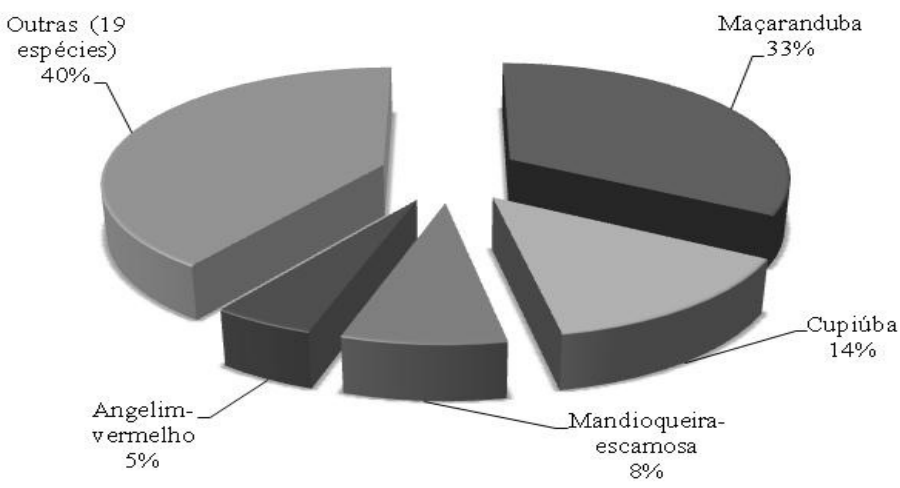

Figura 2. Representação gráfica da frequência (\%) de indivíduos amostrados das espécies florestais na área 590 ha.

Para a avaliação quantitativa da biomassa a fim de obter informações dos resíduos disponíveis (tronco e galhos) foram determinados os volumes estimados para o fuste comercial e o volume da copa das árvores selecionadas durante o manejo florestal, além do volume das espécies que caem juntamente com a árvore principal durante a extração da mesma, de modo que tenha o máximo aproveitamento da árvore.

$\mathrm{O}$ volume total estimado das árvores (fuste e copa) foram efetuados através do volume comercial mais o BEF (biomass expansion factor), que consta na adição da biomassa das copas sobre o volume inventariado do fuste, de acordo com Brown e Lugo (1992). Para realização dos cálculos foram utilizado o diâmetros e a altura do fuste comercial, e a massa específica básica da madeira obtidas com base no banco de dados de madeira do Instituto Brasileiro do Meio Ambiente e dos Recursos Naturais Renováveis - IBAMA,
Mundo Florestal e Nascimento et al. (2006). Determinado o BEF, houve a necessidade de eliminar o peso dos galhos inferiores a $6 \mathrm{~cm}$ e das folhas. Os valores do peso dos galhos e folhas foram calculados com base nos dados do trabalho de Higuchi et al. (1998) e convertido para volume. Pela diferença entre o volume total estimado (fuste e copa) e o volume dos galhos e folhas, encontrou-se um volume total estimado de colheita para um ciclo de rotação de $55,54 \mathrm{~m}^{3} \cdot \mathrm{ha}^{-1}$. Para a determinação do volume comercial estimado utilizado pela empresa, procedeu-se o cálculo a partir do diâmetro e do comprimento da tora comercial, pelo método de Huber. O volume total comercial estimado para as espécies florestais da Orsa Florestal S/A foi de 32,86 $\mathrm{m}^{3} \cdot \mathrm{ha}^{-1}$, na figura 3 pode ser verificado a distribuição do volume comercial estimado para uma área equivalente a um hectare. 


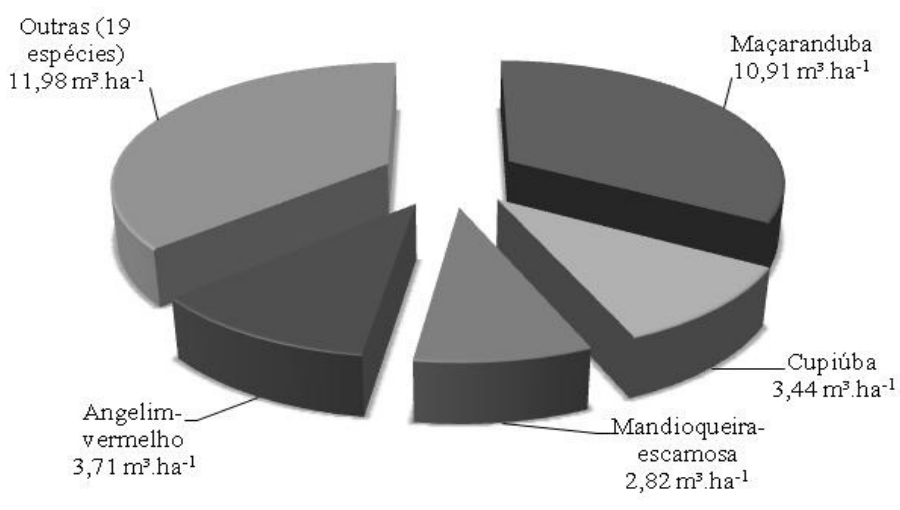

Figura 3. Representação gráfica do volume de madeira comercial estimado das espécies florestais $\left(\mathrm{m}^{3} \cdot \mathrm{ha}^{-1}\right)$.

Dentro desse contexto, foram levantadas informações referentes ao rendimento em madeira serrada e a geração de resíduo das espécies florestais da região amazônica. Na figura 4 verificam-se os percentuais médios encontrados para o rendimento de madeira serrada e a geração de resíduos, e na figura 5 a quantidade de resíduo para diferentes repartições dentro da serraria para espécies florestais da região amazônica. Os percentuais médios foram calculados com base nos dados encontrados nos trabalhos de Santos (2006), Araújo (2003) e Nascimento et al. (2006).

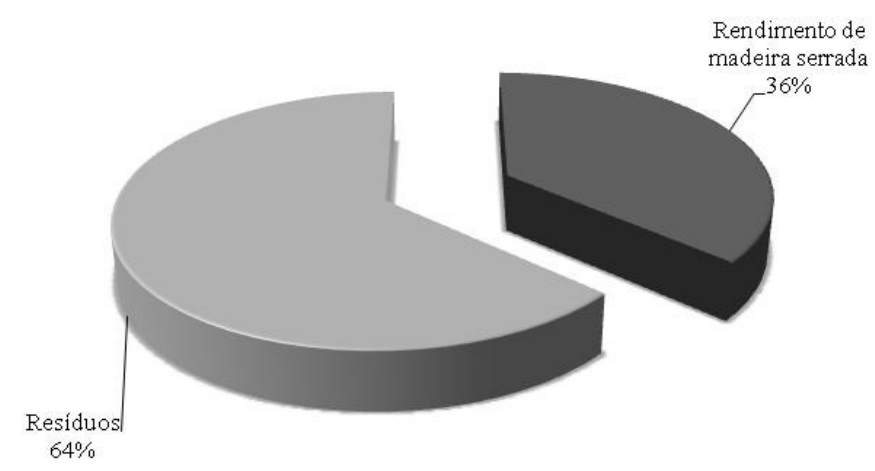

Figura 4. Percentual médio estimado do rendimento da madeira serrada e resíduos. 


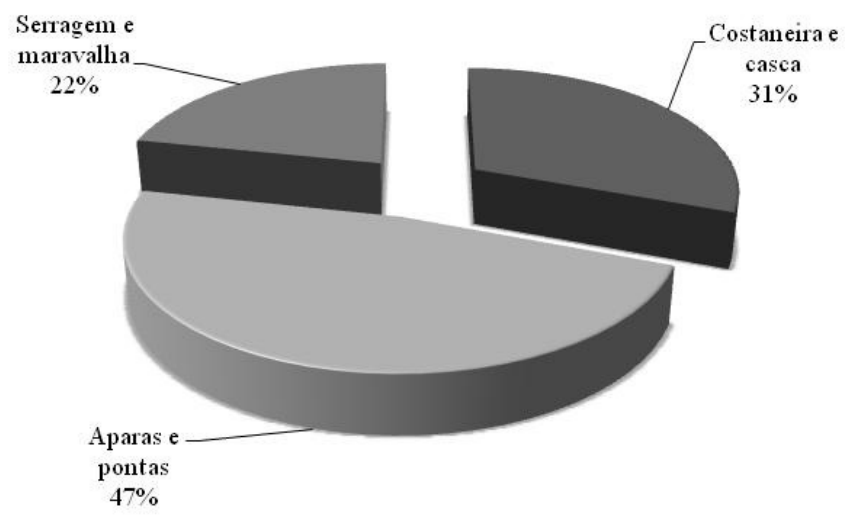

Figura 5. Percentual médio estimado dos resíduos nas diferentes repartições dentro da serraria.

De acordo com Carré et al. (1992), Vidal et al. (1997) e Verissímo et al. (2002), o rendimento do fuste comercial pode variar de $40 \%$ a $65 \%$, isto é, praticamente a metade da tora é transformada em resíduos e isso ocorre muitas vezes em função do tipo da madeira e, também, tecnologias aplicadas. Fontes (1989) cita ainda que o rendimento varia de $25 \%$ a $70 \%$, levando-se em consideração o conjunto de espécies. Para Rocha (2002), o rendimento no desdobro varia de $45 \%$ e $55 \%$ para folhosas, já Pereira et al. (2010) estimaram a produção madeireira da Amazônia Legal no ano de 2009 com rendimento médio de $41 \%$ no processamento.

Para Ferreira et al. (1989), o aproveitamento quantitativo da transformação de uma tora em tábuas, considerando-se uma tora com casca, se dá na ordem de $40 \%$ de madeira processada, sendo os $60 \%$ restantes assim alocados: $10 \%$ de aparas de plaina, $26 \%$ de aparas do corte, $13 \%$ de pó de serra e $11 \%$ de cascas.

De acordo com Mady (2000) o desperdício no setor madeireiro ainda é muito grande, apesar dos avanços tecnológicos. Estima-se que do volume total de uma tora, seja aproveitado cerca de $40 \%$ a $60 \%$, significando que a cada dez árvores cortadas, apenas cinco serão aproveitadas comercialmente.

A partir dos dados analisados, observa-se na figura 6 o percentual estimado do rendimento do volume da matéria prima madeira e a geração dos resíduos florestais distribuídos na cadeia de produção dividida basicamente em três etapas, desde a colheita ao processamento da madeira, nota-se o baixo rendimento final da madeira serrada comparado a colheita. 


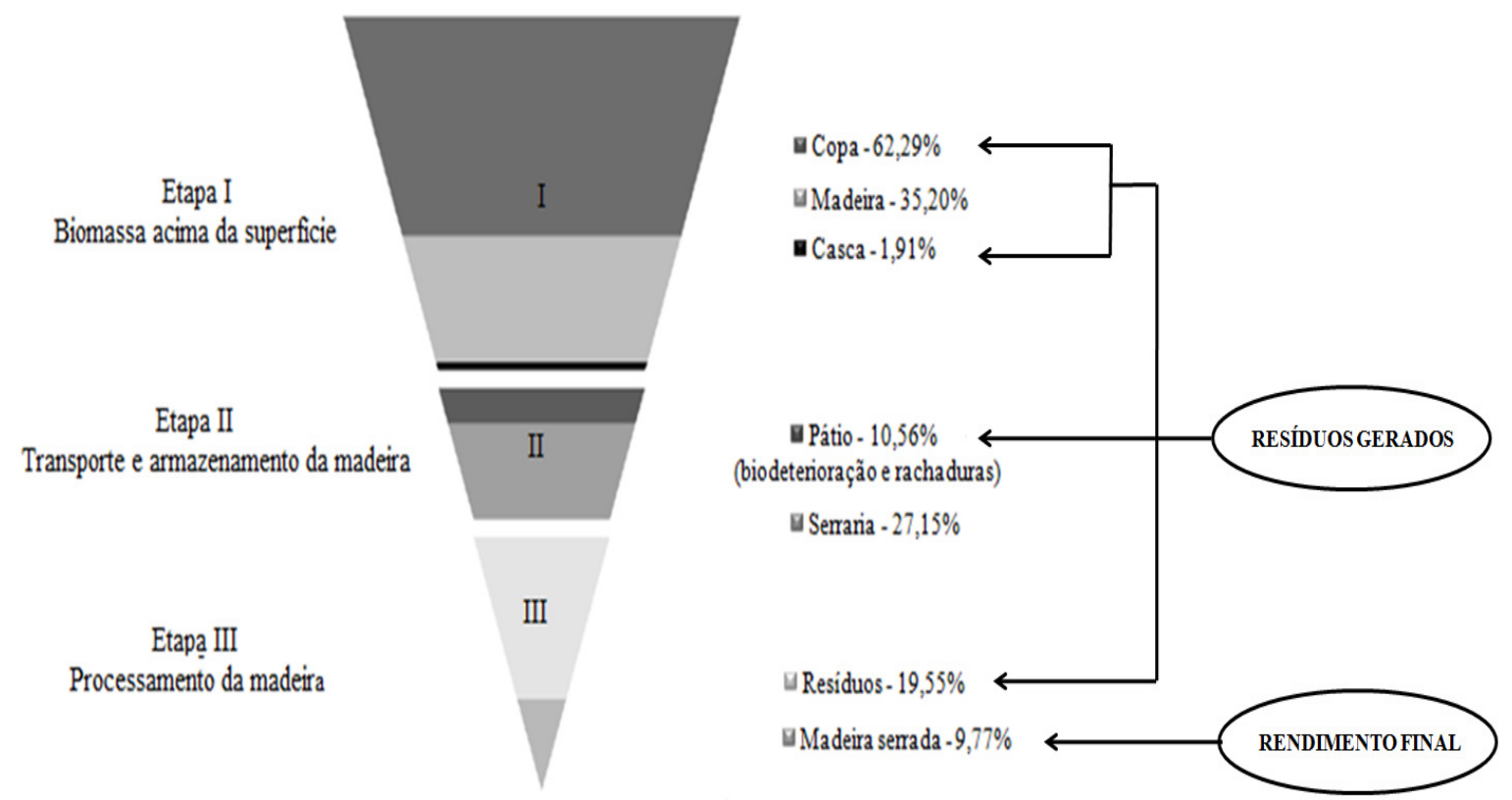

Figura 6. Rendimento da madeira e geração de resíduos estimados na cadeia de produção.

\section{APROVEITAMENTO DOS RESÍDUOS FLORESTAIS E MADEIREIROS}

Segundo Coronel et al. (2007) além da busca de maior eficiência no processo de extração e beneficiamento da madeira, os resíduos não podem mais serem vistos como um problema, ou algo pejorativo resultante do processo industrial e sim uma fonte criativa de matéria-prima para novos produtos.

Para Brand et al. (2002) as indústrias de base florestal têm baixo rendimento e geram grande quantidade de resíduos no processo produtivo, principalmente as indústrias de transformação primária. Os autores ainda ressaltam que $\mathrm{o}$ aumento progressivo da quantidade de madeira desdobrada tem revelado problemas como o crescimento do consumo da matéria-prima madeira.

A Portaria Normativa 302/84 do IBAMA conceitua os resíduos florestais como sobras de material resultante da alteração sofrida pela matéria-prima florestal quando submetida à ação exterior através de processos mecânicos, físicos e/ou químicos.

Para Nolasco (2000), resíduo florestal é estabelecido como todo e qualquer material resultante da colheita ou do processamento da madeira e/ou outros recursos florestais que permanece sem utilização definitiva ao longo do processo, por limitações tecnológicas e de mercados, sendo descartado durante a produção.

Segundo Galvão Filho (2010) os resíduos compreendem restos de tocos, sapopemas (raízes tabulares) e galhos das copas de árvores exploradas no manejo florestal, além de árvores derrubadas involuntariamente durante as operações de derruba e arraste. Como principais fontes geradoras de resíduos de exploração, Barros et al. (2009), citam resíduos gerados pelas copas das árvores exploradas e pelas árvores derrubadas durante a queda das mesmas; resíduos gerados pela abertura de estradas principais, secundárias, trilhas e pátios de árvores do estrado de $10 \mathrm{~cm} \leq$ DAP (diâmetro na altura do peito) $\leq$ $30 \mathrm{~cm}$; resíduos de árvores com DAP $>30 \mathrm{~cm}$ que eventualmente são derrubadas durante a abertura das estradas e pátios; resíduos gerados por queda natural de árvores que se localizam próximo das trilhas de arraste; resíduos de toras ocas ou aparas de fustes deixados no pátio de estocagem e resíduos gerados pela ocorrência de sapopemas (raízes tabulares) em algumas espécies exploradas.

De acordo com Hall et al. (2005) a utilização de resíduos florestais é uma prática bastante conhecida e viável, comercialmente, em muitos países. Segundo Barros et al. (2007), existem muitas fontes de geração de resíduos de exploração florestal deixados nas áreas de 
extração após o término das atividades, as principais são: galhadas das copas das árvores exploradas, árvores derrubadas durante a queda das mesmas, resíduos gerados pela abertura de estradas, trilhas e pátios, queda natural de árvores, resíduos de toras ocas ou aparas de fustes deixados no pátio de estocagem e resíduos gerados pela ocorrência de sapopemas em algumas espécies exploradas.

Valério et al. (2007) ressaltam que para os resíduos do processamento de madeira em serrarias existe a possibilidade de melhor utilização da matéria-prima madeireira por meio da utilização de melhores técnicas, equipamentos e processos. Os mesmos autores recomendam que a utilização da madeira deva ser feita da forma mais racional possível, buscando sempre o máximo rendimento e desenvolvendo novos produtos como alternativa para os resíduos, pois, apesar de ser um recurso natural renovável, a reposição florestal acarreta custos significativos.

$\mathrm{Na}$ exploração florestal utiliza-se quase que exclusivamente o fuste denominado comercial, que vai da base da tora até um diâmetro mínimo pré-estabelecido. Os galhos e os ponteiros das árvores são deixados no campo como resíduos, representando cerca de $20 \%$ da madeira existente na floresta (Brito, 1996). O aproveitamento de toda a árvore pelas indústrias madeireiras está em torno de $30 \%$ a $60 \%$, variando de empresa para empresa (Freitas, 2000).

$\mathrm{O}$ processo de produção da madeira serrada gera um volume significativo de resíduos e sobras oriundas da transformação das toras pelas serras de desdobro e que, somados aos galhos, troncos e raízes que ficam na floresta, indicam um volume significativamente superior ao produto madeireiro obtido. Do ponto de vista tanto econômico como ambiental se justificariam programas, envolvendo incentivos e facilidades, para a instalação de linhas de aproveitamento destas sobras e resíduos desde a geração de energia a partir desta biomassa até aqueles destinados à obtenção de produtos com agregação de valor (Fagundes, 2003)

O rendimento da matéria-prima (galhos de copa) em madeira serrada varia bastante entre as espécies e dentro da mesma espécie. Os fatores inerentes à qualidade, à classe diamétrica das toras e o tipo de produto final, influenciam, diretamente, nos valores de rendimento. Desta forma, qualquer predição de produção deve levar em consideração estas variações. $\mathrm{O}$ aproveitamento e o beneficiamento da madeira serrada através de processamento mecânico sofre variação, também, de acordo com o nível tecnológico da indústria, da qualidade da matéria prima, da espécie e de outros fatores (ABIMCI, 2003)

Segundo Rocha (2002) e Stelle (1984), o rendimento pode ser afetado conforme a espécie que está sendo desdobrada, pela qualidade dos povoamentos de onde as árvores são provenientes, diâmetro, conicidade e comprimento das toras, eliminação de defeitos na tora, subprodutos retirados a partir do desdobro, os equipamentos e técnicas utilizados no desdobro e a qualidade profissional dos operários.

Diversos autores (ABIMCI, 2009; Brand, 2002; Lentini et al., 2005; Sabogal et al., 2006) citam que o aproveitamento do resíduo florestal proporciona o desenvolvimento em áreas rurais, podendo melhorar a situação econômica das comunidades e populações locais, através da geração de renda e fluxo monetário, beneficiando o meio ambiente com a diminuição da pressão sobre as florestas em pé, pois, na maioria das vezes, sua exploração é feita de forma predatória.

Garcia (2011) considera que aproveitamento de resíduos das galhadas de árvores exploradas para fins de madeira serrada é uma alternativa que agrega valor ao resíduo que antes era vendido na sua forma bruta, agora poderá ser beneficiado e vendido a um valor maior. Segundo o mesmo autor, os resíduos de copas de árvores são, em potencial, uma oportunidade para uso nas indústrias de transformação para desdobramento em madeira serrada, gerando produtos e subprodutos para o mercado. Para isso faz-se necessário, inicialmente, quantificar essa biomassa para conhecer o potencial de galhadas deixadas na floresta.

A madeira caída também é uma fonte de matéria prima, de acordo Rocha (2010) no contexto moderno de comercialização de serviços ambientais e produtos florestais com origem sustentável comprovada, o aproveitamento da madeira caída pode ser uma atividade oportuna. $\mathrm{O}$ autor ainda ressalta que por se tratar de um material orgânico, com diversos constituintes, para o melhor emprego da madeira, as espécies devem ser estudadas quanto ao seu nível de toxidez a fim de evitar futuros problemas mais graves aos consumidores e usuários.

No caso da utilização de resíduos florestais na floresta amazônica existem vários fatores importantes a considerar. Muitas vezes os 
chamados "resíduos florestais" não são utilizados por falta de opções tecnológicas que permitem o uso racional dessa matéria prima dentro das limitações econômicas dos proprietários florestais, ou porque o uso total da biomassa põe em risco o equilíbrio ecológico destes sensíveis ecossistemas. Ninguém sabe avaliar qual seria o impacto da retirada adicional de biomassa da copa para o balanço de nutrientes, a compactação do solo ou a qualidade das árvores remanescentes. Vários estudos internos de empresas que praticam o manejo sustentável dentro da lei vigente demonstraram que a colheita e o transporte de resíduos da copa não compensam economicamente, pois sob as condições atuais os custos superam o valor da matéria prima de forma significativa. Uma das conclusões mais importantes desta situação é a necessidade de pesquisar com prioridade novas tecnologias para a colheita da biomassa proporcionando baixo impacto e as possibilidades tecnológicas para beneficiar a matéria prima ainda na floresta para melhorar a relação entre custo e benefício do material transportado.

Em outros países, por exemplo, na Europa, o desejo da sociedade em fazer melhor uso dos recursos naturais e de matéria prima renovável, é incentivado com subsídios para a cadeia produtiva, compensando assim a baixa competitividade do uso da madeira para fins energéticos. As energias fósseis tem uma vantagem de dezenas de anos a frente das energias renováveis, tais como na logística, redes de distribuição e tecnologias de combustão.

\section{CONSIDERAÇÕES FINAIS}

$\mathrm{O}$ uso da terra e demais atividades como a exploração madeireira sem plano de manejo, queimadas, cultivos agrícolas e pecuárias de forma errônea e ilegal comprometem a Floresta Amazônica, assim, contribuindo para sua devastação e escassez. O manejo florestal sustentável junto com a fiscalização de forma responsável é de grande importância para a garantia de uma produção contínua de madeira de forma racional, garantindo a conservação e preservação da biodiversidade dos recursos florestais na região amazônica.

$\mathrm{O}$ aproveitamento dos resíduos florestais e madeireiro é uma atividade que contribui para o manejo sustentável, agregando valor ao subproduto. Sabe-se do elevado desperdício dos resíduos desde árvores caídas durante a extração das mesmas, até o processamento da madeira nas serrarias, isso ocorre em função da falta de interesse e tecnologia para o seu aproveitamento.

Portanto, novos estudos com intuito de obter alternativas e tecnologias para o uso dos resíduos florestais devem ser alcançados. O desenvolvimento de alternativas deve ser priorizado, disponibilizada, testadas e viáveis para que se possa minimizar o desperdício da madeira, fazendo uso eficiente da biomassa, agregando valor, além dos benefícios ambientais, econômicos e sociais que podem ser gerados na região. As atividades de pesquisas devem se aliadas as condições da região, o aproveitamento dos resíduos florestais além de colaborar para o manejo sustentável da floresta amazônica assegurando a sua sobrevivência pode contribuir também para a geração de renda nas comunidades. Além do uso dos resíduos para a fabricação de painéis, geração de energia, compostagem e produção de pequenos objetos de madeira entre outros, uma alternativa que esta sendo estudada para contribuir com a redução do desperdício é a obtenção de nanocelulose a partir dos resíduos disponíveis oriundos das operações da colheita florestal e do processamento da madeira, dentro de um manejo florestal sustentável aliado a logística de transporte $\mathrm{e}$ às viabilidades econômicas.

Grande parte do desperdício são justamente originados pela falta de planejamento, implementação de novas tecnologia e técnicas adequadas que devem ser colocadas em práticas dentro da gestão de florestas sustentáveis. Portanto, novas formas de utilização para o aproveitamento dos resíduos florestais devem ser inseridas, a fim de acabar com os problemas de desperdício de matéria prima, agregando valor e elevando a demanda de novos produtos, tecnologias e serviços de forma sustentável, assegurando a conservação dos recursos naturais.

\section{AGRADECIMENTOS}

Os autores agradecem ao Programa Novas Parcerias (NoPa) CAPES/DAAD/GIZ

\section{REFERÊNCIAS}

Araujo HJB. Aproveitamento de resíduos das indústrias de serraria do acre para fins energéticos. Rio Branco: Documento 82, EMBRAPA, 2003. 
Associação brasileira de indústria de madeira processada mecanicamente - ABIMCI. Produtos de madeira sólida. Estudo Setorial, 2003.

Associação brasileira de indústria de madeira processada mecanicamente - ABIMCI. Produtos de madeira sólida. Estudo Setorial, 2008. Ano base 2007.

Associação brasileira de indústria de madeira processada mecanicamente - ABIMCI. Produtos de madeira sólida. Estudo Setorial, 2009. Ano base 2008.

Associação brasileira de indústria de madeira processada mecanicamente - ABIMCI. Fórum nacional das atividades de base florestal. Resíduos de madeira geradores de receita. Artigo técnico, 2009.

Baggio AJ, Carpanezzi AA. Quantificação dos resíduos florestais em bracatingais na região metropolitana de Curitiba, PR. Boletim Pesquisa Florestal, v. 30/31, p. 51-66, 1995.

Barbosa AP, Vianez BF, Varejão MJ, Abreu RLS. Considerações sobre o perfil tecnológico do setor madeireiro na Amazônia Central. Biodiversidade, pesquisa e desenvolvimento na Amazônia, 2001.

Barros AC, Veríssimo AA. A expansão madeireira na Amazônia: Impactos e perspectivas para o desenvolvimento do Pará. Instituto do Homem e Meio Ambiente da Amazônia - IMAZON. Belém; 2002.

Barros AC, Uhl C. Logging along the Amazon River and estuary: patterns, problems and potential. Forest Ecology and Management, v. 77, p. 87-105, 1995.

Barros PLC, Numazawa S, Barros DS. Quantificação de resíduos de exploração e de árvores de queda natural em florestas manejadas na Amazônia: O caso Cikel Brasil Verde Madeiras. Relatório técnico; 2007.

Barros PLC, Numazawa S, Ferreira JER, Barros DS. Resíduos de exploração em florestas manejadas na Amazônia: O caso Cikel Brasil Verde Madeiras. Relatório técnico; 2009.

Brand MA, Muñiz GIB, Silva DA, Klock U. Caracterização do rendimento e quantificação dos resíduos gerados em serraria através do balanço de materiais.Revista Floresta, v.32, n.2, p. 247-259, 2002

Brasil. Resolução CONAMA n. 406, de 2 de fevereiro de 2009. Estabelece parâmetros técnicos a serem adotados na elaboração, apresentação, avaliação técnica e execução de Plano de Manejo Florestal Sustentável - PMFS com fins madeireiros, para florestas nativas e suas formas de sucessão no bioma Amazônia. Diário Oficial da União, 26, (2009 fev. 6):100.

Brown S, Lugo AE. Aboveground biomass estimates for tropical moist forests of the Brazilian Amazon. Interciencia, v. 17, p. 8-18, 1992.

Brito EO. Estimativa da produção de resíduos na indústria brasileira de serraria e laminação. Revista Floresta, v.26, n.4, p. 34-39, 1996.

Carré JEl, SchenkeL EC. Biomass Characteristics and combustion process In: Proceedings of the E.C. workshop: Designs and selection of biomass boilers; 1992; Yogojakarta; 1992.

Coronel DA, Lago A, Lengler L, Silva TN. O aproveitamento dos resíduos do setor florestal de Lages- Santa Catarina. In: XLV Congresso da SOBER - Sociedade Brasileira de Economia, Administração e Sociologia Rural; 2007; Paraná: Londrina, 2007, p.14.

Fagundes HAV. Diagnóstico da produção de madeira serrada e geração de resíduos do processamento de madeira de florestas plantadas no rio grande do sul [dissertação]. Porto Alegre, RS: Universidade Federal do Rio Grande do Sul; 2003.

Fearnside PM, Tardin AT, Meira Filho LG. Deforestation Rate in Brazilian Amazon. Instituto de Pesquisas Espaciais, Secretária da Ciência e Tecnologia; 1990.

Ferreira CEM, Carrasco EVM, Helmeister JC. Tecnologia de adesivos poliuretanos: propriedades e aplicações em madeiras. In: Anais Encontro Brasileiro em Madeiras e Estruturas de Madeiras. São Carlos, São Paulo: LaMEM/EESC-USP, 1989. p. 39- 74.

Fontes PJP. Aproveitamento energético da madeira derivada dos desmatamentos em Rondônia. Brasília: IBAMA/DIRPED/LPF; 1989, p. 9.

Freitas LC. A baixa produtividade e o desperdício no processo de beneficiamento da madeira: um estudo de caso [dissertação]. Florianópolis, SC: Universidade Federal de Santa Catarina; 2000.

Freitas M. Amazônia e Desenvolvimento Sustentável: um diálogo que todos os brasileiros deveriam conhecer. Petrópolis: Vozes; 2004.

Galvão Filho A F. Avaliação da aplicabilidade do método de amostragem por linhas interceptadoras na quantificação de resíduos de exploração florestal nas condições de uma floresta de terra firme na Amazônia 
brasileira [dissertação]. Belém, PA: Universidade Federal Rural da Amazônia; 2010.

Gama JRV, Bentes-Gama MM, Scolforo JR. Manejo sustentado para floresta de várzea na Amazônia Oriental. Revista Árvore, v. 29, n.5, p. 719-729, 2005

Garcia IMW. Quantificação e rendimento de resíduos aproveitáveis para madeira serrada da copa das árvores provenientes de exploração florestal [dissertação]. Belém, PA: Universidade Federal Rural da Amazônia; 2011.

Gonçalves FG, Santos JR. Composição florística e estrutura de uma unidade de manejo floresta sustentável na Floresta Nacional do Tapajós, Pará. Acta Amazonica, v. 38, n. 2, p. 224-229, 2008.

Hall DO, House, JI, Scrase I. Visão geral de energia e biomassa. In Rosillo-Cale, Bajay E Rothman. Uso da Biomassa para Produção de Energia na Indústria Brasileira. Campinas, São Paulo: Editora da UNICAMP, 2005.

Higuchi N. Utilização e manejo de recursos madeireiros das florestas tropicais úmidas. Acta Amazônica, v. 204, n.3/4, p. 275-278, 1994.

Higuchi N, Santos J, Ribeiro R.J, Minette L, Biot Y. Biomassa da parte aérea da vegetação da floresta tropical úmida de terra-firme da Amazônia brasileira. Acta Amazonica, v. 28, n. 2, p.153-166, 1998.

Higuchi NA. Exploração Seletiva de Madeira na Amazônia Brasileira: sua Relação com o Desmatamento e o Mercado Internacional de Madeira Dura Tropical. In..: Relatório Final BIONTE;:1997;1330.

Higuchi N, Santos J, Teixeira LM, Lima AJN. O mercado internacional de madeira tropical está à beira do colapso. SBPN v. 1, n. 2, p. 33-41, 2006.

Higuchi, N.; Santos, J. dos; Silva, R. P. da; Lima, A. N.; Teixeira, L. M.; Carneiro, V. M. C.; Felsemburgh, C. A.; Tribuzy, E. S. Noções básicas sobre manejo florestal. Grupo de pesquisas em manejo florestal/INPA. 2008. (APOSTILA). 270 p

Instituto Brasileiro do Meio Ambiente e dos Recursos Naturais Renováveis-IBAMA. Disponível em http://www.ibama.gov.br/lpf/madeira/

Instituto Brasileiro de Qualidade e Produtividade do Paraná - IBQP Análise da competitividade da cadeia produtiva da madeira no estado do Paraná. Curitiba; 2002. p.345.
Lentini M, Pereira D, Celentano D, Pereira R. Fatos Florestais da Amazônia. Instituto do Homem e Meio Ambiente da Amazônia - IMAZON. Belém; 2005.

Macpherson AJ, Lentini MW, Carter DR, Baitz WN. Eficiência de serrarias na Amazônia: uma análise por envoltória de dados. Scientia. Forestalis, v. 37, n. 84, p. 415-425, 2009.

Mady FTM. Conhecendo a madeira: informações sobre 90 espécies comerciais. Programa de Desenvolvimento Tecnológico. SEBRAE; 2000.

Martins SS, Couto L, Machado CC, Souza A L. Efeito da exploração florestal seletiva em uma floresta estacional semidecidual. Revista Árvore, v. 27, n. 1, p. 65-70, 2003.

Mundo florestal. Disponível em http://www.mundoflorestal.com.br

Nascimento SM, Dutra RIJP, Numazawa S. Resíduos de indústrias madeireiras: caracterização, consequência sobre o meio ambiente e opções de uso. Holos environment, v. 6, n. 1, p.9, 2006.

Nolasco, A.M. Resíduos da colheita e beneficiamento da caixeta - Tabebuia cassinoides (Lam.) DC.: caracterização e perspectivas [tese]. São Carlos, SP: Escola de Engenharia de São Carlos, Universidade de São Paulo; 2000.

Nutto L, Spathelf P, Schroeder UE. Sustainable Forest Management in the Tropics - Still a Long Way to Go? In: Sustainable Forest Management in a Changing World: a European Perspective. Springer-Verlag; 2009.

Organización Internacional de las Maderas Tropicales OIMT. Reseña anual y evaluación de la situación mundial de las maderas. Yokohama; 2006.

Oliveira NA, Amaral IL. Florística e fitossociologia de uma floresta de vertente na Amazônia Central, Brasil. Acta Amazônica, v. 34, n. 1, p. 21-34, 2004.

Pereira D, Santos D, Vedoveto M, Guimarães J, Veríssimo A. Fatos Florestais da Amazônia 2010. Instituto do Homem e Meio Ambiente da Amazônia IMAZON.Belém; 2010.

Pontes SMA, Afonso DG, Nascimento DL. Análise comparativa das propriedades físico-mecânicas da madeira de galho e fuste de 02 espécies florestais com potencial madeireiro. In: Anais $4^{\circ}$ Congresso Florestal; 2012. Curitiba. Paraná: 2012. 
Pontes SMA, Afonso DG. Análise da viabilidade técnica do aproveitamento dos resíduos florestais. . In: Anais Encontro Brasileiro em Madeiras e Estruturas de Madeiras; 2010.

Rankin JM. Forestry in the Brazilian Amazon. In: Prance, G, Lovejoy, T. editors. Amazonia, key environmental series. Oxford: Pergamon Press; 1985.

Reis LP, Ruschel AR, Coelho AA, Luz AS, Martinsda-Silva RCV. Avaliação do potencial madeireiro na floresta nacional dos tapajós, após 28 anos da exploração florestal. Pesquisa Florestal Brasileira, v. 30, n.64, p. 265-281, 2010.

Reis MS. A Indústria Baseada em Madeiras Duras no Brasil. Mesa Redonda Internacional: Oportunidades e Limitações para o Desenvolvimento da Indústria Baseada em Madeiras Tropicais na América Latina: Brasília; 1989.

Remade. Os Desafios da gestão das florestas naturais. Revista da Madeira, v.108, p.11-25, 2007. Disponível em

http://www.remade.com.br/br/revistadamadeira_mat eria.php?num=1154\&subject=Recursos.

Rocha MP. Técnicas e planejamento em serrarias. Curitiba: Fundaçăo de Pesquisas Florestais do Paraná; 2002

Rocha JA. Madeira caída como oportunidade para o manejo florestal comunitário em unidades de conservação no amazonas, Brasil [dissertação]. Manaus, AM: Instituto Nacional de Pesquisa da Amazônia - INPA; 2010.

Sabogal C, Lentini M, Pokorny B, Silva JN, Zweede J, Veríssimo A, Boscolo M. Manejo florestal empresarial na Amazônia Brasileira: restrições e oportunidades. Belém:CIFOR; 2006.p.74.

Santos RC. Levantamento de resíduos da indústria madeireira do Acre. Rio Branco: FUNTAC; 2006.p.51.

Schneider PR, Finger CAG. Manejo sustentado de florestas inequiâneas heterogêneas. Santa Maria, Rio Grande do Sul. Santa Maria: CEPEF; 2000.

Scolforo JRS, Pulz FA, Mello JM, Oliveira Filho AT. Modelo de produção para floresta nativa como base para manejo sustentado. Revista Cerne, v. 2, n. 1, p.112-137, 1996.

Serviço Florestal Brasileiro (SFB); Instituto do Homem e Meio Ambiente da Amazônia (IMAZON). A atividade madeireira na Amazônia brasileira: produção, receita e mercados. Relatório CDD: 333.7509811, 32p; 2010.

Smith DM, Larson BC, Kelty MJ, Ashton PM. The pratictice of silviculture: applied forest ecology. New York: Willey and Sons; 1997.

SILVA, K. E.; RIBEIRO, C. A. A. S.; MARTINS, S. V.; SANTOS, N. T. Concessão de florestas públicas na Amazônia: Desafios para o uso sustentável dos recursos florestais. Bioikos, Campinas, 23(2):91-102, jul./dez., 2009.

Sist P, Ferreira FN. Sustainability of reduced-impact logging in the Eastern Amazon. Forest Ecology and Management, v. 243, p. 199-209, 2007.

Steele PH. Factors determining lumber recovery in sawmilling. Madison: Forest Service, Forest Products Laboratory; 1984.

Valério AF, Watzlawick LF, Santos RT, Brandelero C, Koehler HS. Quantificação de resíduos e rendimento no desdobro de Araucaria ngustifolia (bertol.) O. Kuntze. Revista Floresta, v.37, n.3, p. 387-398, 2007.

Verissimo A, Barreto P, Tarifa R, Uhl C. Extraction of a high-value natural resource from Amazonia: the case of mahogany. Forest Ecology and Management, v.58, p. 39-60, 1995.

Veríssimo A, Lentini M, Lima E. Pólos madeireiros do Estado do Pará. Belém: IMAZON, 2002.

Vidal E, Barreto P, Johns J, Gerwing J, Uhl C. Vine management for reduced-impacts logging in Eastern Amazon. Forest ecology and management, v. 98, p. 105-114, 1997.

Uhl C, Barreto P, Veríssimo A, Vidal E, Amaral P, Barros AC, Souza Jr C, Johns J, Gerwing J. Natural resource management in the Brazilian Amazon. Bioscience, v. 47, p. 160-168, 1997.

Zarin D, Pereira VFG, Raffles H, Rabelo FG, PinedoVasquez FG, Congalton RG. Landscape change in the tidal floodplain near the mouth of the Amazon River. Forest Ecology and Management, v. 154, p. 154: 383-393, 2001.

Recebido: $15 / 08 / 2013$

Received: 08/15/2013

Aprovado: 25/10/2013

Approved: 10/25/2013 